\title{
POTENTIAL MALE GAMETOPHYTE COMPETITION AMONG CAMELLIA SINENSIS GENOTYPES IN ISOLATED BICLONAL SEED ORCHARDS
}

\author{
R.C. MUOKI, F.N. WACHIRA ${ }^{1 *}$, R. PATHAK ${ }^{2}$ and S.M. KAMUNYA \\ Tea Research Foundation of Kenya, P. O. Box 820, Kericho, Kenya \\ ${ }^{1}$ Department of Biochemistry and Molecular Biology, Egerton University, P. O. Box 536, Egerton, Kenya \\ ${ }^{2}$ Department of Crop, Horticulture and Soil Sciences, Egerton University, P. O. Box 536, Egerton, Kenya
}

(Received 17 February, 2007; accepted 17 June, 2007)

\begin{abstract}
Male fertility of crop plants is a function of pollen production and viability. In breeding, it is a requirement that there be similar fertilities among breeding parents within seed orchards. An in-vitro germination method was used in this study to determine variation in pollen viability among eight tea (Camellia sinensis) genotypes, over three flowering seasons in four isolated biclonal seed orchards located at two sites. The effect of environmental conditions on pollen germination was also studied on two popular genotypes, i.e. AHP SC31/37 (an assamica variety) and GW Ejulu-L (a sinensis variety) that were planted in both sites. Significant variation $(\mathrm{P}<0.05)$ in pollen viability among the eight genotypes indicated a potential for male gametophyte competition. There was significant genotype by environment interaction and positive correlation between pollen viability and temperature. Pollen germination was, however, not affected by rainfall and humidity. The variations in pollen viability may contribute to the variable genetic composition of seed produced in the isolated seed orchards of tea.
\end{abstract}

Key Words: In-vitro germination, male fertility, pollen viability

\section{RÉSUMÉ}

La fertilité mâle de plantes culturales est fonction de la production et de la viabilité polliniques. Lors de culture, il est une nécessité que les seuils de fertilité soient similaires parmi les parents des cultures au sein de vergers de semences. Une méthode de germination in vitro était utilisée dans cette étude en vue de déterminer la variation en viabilité de pollen parmi 8 génotypes de thé (Camelia sinensis) de par 3 saisons de floraison dans 4 vergers de semences bi clonaux situés au niveau de 2 sites. Les effets des conditions environnementales sur la germination du pollen étaient également étudiées; sur 2 génotypes populaires c'est-à-dire AHP SC 31/37 (une variété assamica) et GW Ejulu - L (une variété sinensis) qui étaient plantées sur les 2 sites. Des variations significatives $(\mathrm{P}<0,05)$ en viabilité de pollen parmi les 8 génotypes indiquaient un potentiel pour la compétition de gamétophyte mâle. Il y avait une interaction significative genotype par environnement et une corrélation positive entre viabilité de pollen et température. La germination du pollen n'était cependant pas affectée par les pluies ou par l'humidité. Les variations en viabilité de pollen pourraient contribuer à la composition génétique variable de semences produites dans les vergers isolés de semences de thé.

Mots Clés: In-vitro, germination, fertilité mâle, viabilité de pollen.

\section{INTRODUCTION}

Tea (Camellia sinensis (L.) O Kuntze) breeding is largely dependent on the use of natural open pollination as medium for gene recombination due to the inefficiencies associated with artificial pollination techniques. However, like in most plants, progress in tea breeding continues to be constrained by low seed yields which in part is ascribed to inadequate pollen transfer by the 
pollination vectors (Free, 1993) as well as possible pollination between closely related varieties (biparental inbreeding) resulting in low fruit set, small fruits and sterile seeds (Wachira and Kamunya, 2005). Pollen source and its viability are, therefore, important considerations for maximising tea sea production.

Tea is pollinated by insects as such, the amount of pollen deposited on the stigma can be influenced by the spatial isolation and small population size of breeding parents, both of which generally act to reduce the frequency of pollinator visitation (Hodgins and Barrett, 2006). In open pollinated species, pollinator foraging distances are generally negatively correlated with plant density (Kameyama et al., 2002). The reproductive potential or capacity of a plant in also dependent on the numbers of inflorescence, pollinated flowers and fertilised ovules, the extent of fruit or seed predation, weather conditions and the ability of the maternal parent to provide resources for development (Gaol and Fox, 2002).

Recent studies have demonstrated that most plant species suffer, at times, from pollen or pollinator limitation considered important to maximise fruit yields (Wilcockc and Neiland, 2002; Farwig et al., 2004). Generally, higher but not excessive numbers of pollen grains and beneficial for optimal seed and fruit production since pollen competition, ovule and seed abortion, pollen tube attrition and physical blockage of pollen grains limit the number of successful fertilisations and seed set (Dogterome et al., 2000). Wachira and Kamunya (2005) found that the cross and self pollen tubes of tea grow at different rates and compete to fertilise the ovule. This pollen competition results in ovule fertilisation by the faster pollen tubes. In Zucchibni squash, this results in better quality seeds and fruits, since faster pollen tubes are more successful at fertilising ovules (Davis et al., 1987). Kutubidze (1958) reported that supplementary pollination (i.e. extra-pollen) produced more, larger and heavier capsules; better viability and higher grade of seed in tea.

The fitness of male gametophytes depends both on paternal traits, which include phenology of male flowering and the amount of pollen produced, and pollen grain traits, such as the germination percentage, germination time, pollen tube growth rate and selective fertilisation (Nikkanen et al., 2000). In most plants, variations in temperature, humidity and cloud cover can influence pollen production and viability (McLaren and Wehner, 1992). Cold temperatures stress prior to flowering in sorghum (sorghum spp.) reduces pollen viability during anthesis by disrupting meiosis during the early stages of microsporogenesis (Brooking, 1979). The physiological effects of environmental factors such as low or high temperature stresses, humidity and cloud cover on male fertility of tea are, however, not as well characterised.

Pollen viability can be quantified by different procedures. Under field conditions, it can be tested in-vivo by evaluating seed set on self-or cross-pollinated florets. This particular measurement may indicate the presence or absence of fertile pollen. Under laboratory conditions, viability can be quantified more precisely by simple assays such as the evaluation of pollen germination in vivo (Sun et al., 1991) or in vitro Lansact et al. (1994); use of vital stains including aniline blue to detect the glucopyranose callose in pollen tubes, or iodine to determine starch content (Brooking, 1979; Heslop-Harrison et al., 1984; Wachira and Kamunya, 2005). In vitro pollen germination is generally believed to provide the best estimate of pollen viability in vivo (Stone et al., 1995).

The objective of this study was to determine whether there was variation in pollen viability within and between the three cultivated tea taxa, i.e., China, Assam and Cambod varieties and whether such variation if found was related to some environmental factors and underlying genetic viability in tea.

\section{MATERIALSAND METHODS}

Sites and plant materials. The experiment was carried out in four isolated tea biclonal seed orchards (with two clones each) of the Tea Research Foundation of Kenya (TRFK). Two of the orchards were located at Timbilil, Kericho district ( $0^{\circ} 22^{\prime} \mathrm{S}$ and $35^{\circ} 21^{\prime} \mathrm{E}$, elevation $2020 \mathrm{~m}$ a.m.s.l) (Table 1). The germplasm in the seed orchards consisted of six different genotypes namely; TRFK 6/8, AHP SC 31/37, TRFCA SFS 150, GW Ejulu-L, TRFK 301/5 and TRFK 301/4 
TABLE 1. Description of Camellia sinensis genotypes studied in four isolated seed orchards

\begin{tabular}{llll}
\hline Orchard site & Genotype/Clone & Variety type & Important attributes \\
\hline Timbilil & TRFK 6/8 & Chinary/Assamica & High quality \\
$($ Kericho) & AHP SC 31/37 & Assamica & High yield, pest resistant \\
Timbilil & TRFCA SFS 150 & Assamica & Pest/cold/drought tolerant \\
(Kericho) & GW Ejulu-L & China or sinensis & High quality \\
Kangaita & TRFK 301/5 & Cambodiensis & High yield, RKN resistant \\
(Kiriinyaga) & GW Ejulu-L & Chinary or sinensis & High quality \\
Kangaita & TRFK 301/4 & Cambodiensis & High yield \\
(Kirinyaga) & AHP SC31/37 & Assamica & High yield, pest resistant \\
\hline
\end{tabular}

Delineation of variety type based on morphological traits; RKN = Root knot nematode

with genotypes AHP SC 31/37 and GW Ejulu-L being present at both sites.

The seed orchards, 0.08 ha each, were all established in 1998. They were designed with three breeding ramets of each genotype arranged in an alternating pattern at the centre and surrounded by a pollen dilution zone (i.e. a living wall) approximately $20 \mathrm{~m}$ wide. The pollen dilution zone consisted of hedge comprised of the two genotypes and was expected to effectively eliminate pollen contamination (gene migration).

Ten to twenty freshly opened flowers per genotype bush were randomly harvested from the three breeding bushes within a seed orchard and used as a source of pollen in this experiment. Each bush was considered a replication. The species flowered during March to August. All flowers were collected between 0900 and $1000 \mathrm{~h}$ with the mean daily maximum and minimum temperatures and other weather parameters, i.e. altitude, rainfall and relative humidity were registered. Pollen were collected over three flowering seasons, i.e., early March, mid- May and late July in 2005 and 2006.

Pollen germination and viability. Pollen viability was estimated using a modified method of Tuinstra and Wedel (2000). This was by suspending dry pollen in a petri-dish with a paper towel soaked in $1 \mathrm{ml}$ of $30 \%$ sucrose (W/V sucrose) with $1.5 \mathrm{mgl}^{-1}$ borate as sodium tetraborate for 24 hours. The germination temperature $\left(25^{\circ} \mathrm{C}\right)$ and illumination (15 Lux) were controlled by incubating the pollen in a growth cabinet. After incubation, counts were made at random in three microscopic fields (each with a minimum of 50 pollen grains per replication) under a low power magnification (X6.3) and rated as germinated or non-germinated. Pollen grains were considered germinated when the pollen tube had gained a length equal to or longer than the diameter of the pollen grain (Fig. 1). The percentage germination was obtained as:

Statistical analysis. The arcsine transformation was applied to data over the two years prior to statistical analysis. Analysis of variance was performed in a completely randomised design using GENSTAT (1987) for each flowering season. The relationship between two of the genotypes that were common at both test sites and the environmental conditions of these sites over the three flower sampling seasons were assessed using linear regression $(\mathrm{P}<0.05)$.

\section{RESULTS}

There was significant $(\mathrm{P}<0.05)$ variation in pollen viability among and between the Camellia sinensis genotypes in the seed orchards (Table 2). After 24 hours in-vitro germination, pollen germination varied from $44.1 \%$ for genotype $\mathrm{GW}$ Ejulu-L at Timbilil, to $51.2 \%$ for genotype AHP SC 31/37 at Kangaita with a mean germination of $48.5 \%$ for both sites. There was also significant $(\mathrm{P}<0.05)$ seasonal variation in pollen grain germination (Table 2). Seasonal pollen germination ranged from $44.2 \%$ during the later season to $50.7 \%$ in the mid-seaon. 


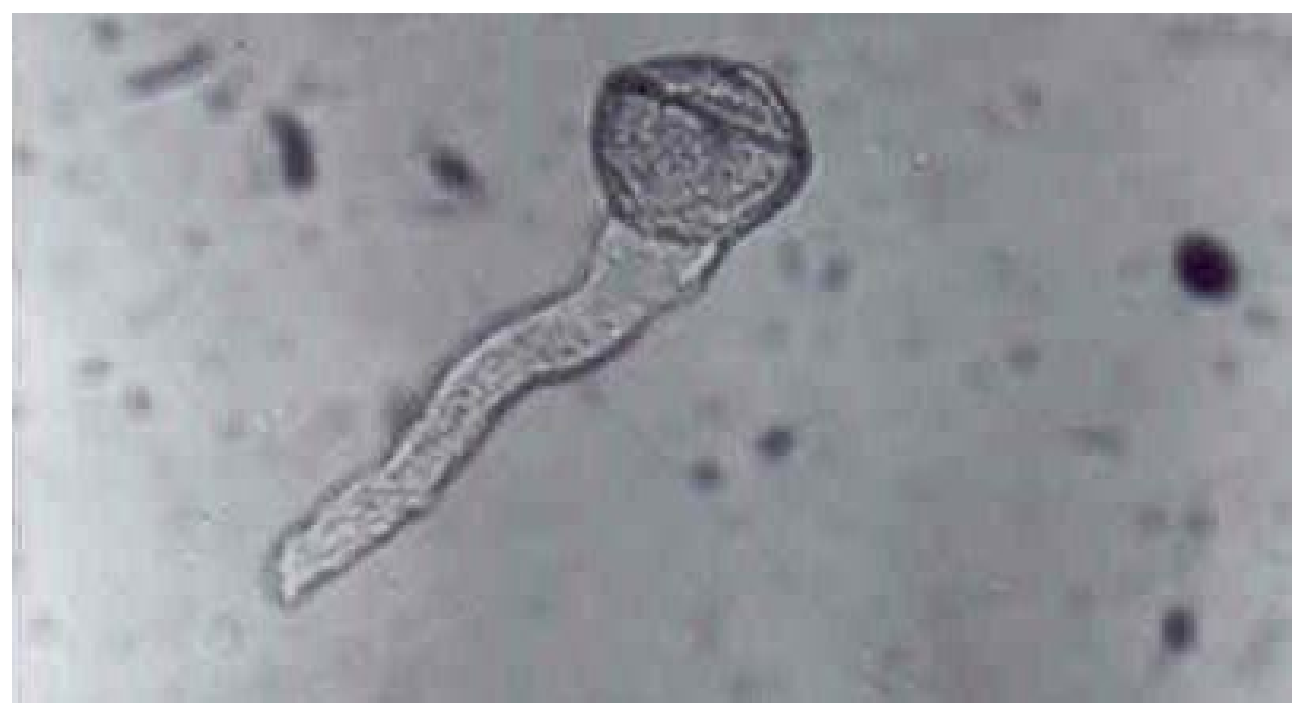

Figure 1. In-vitro tea germination during the study.

TABLE 2. Pollen viability (arcsine transformed data) over three flowering seasons (early, mid and late) in eight tea genotypes

\begin{tabular}{|c|c|c|c|c|}
\hline \multirow{2}{*}{ Clone } & \multicolumn{4}{|c|}{ Mean pollen germination (\%) } \\
\hline & Early & Mid & Late & Mean \\
\hline TRFK 6/8 & $51.2^{(a b)}$ & $56.1^{(a)}$ & $41.3^{(\mathrm{cd})}$ & $49.4^{\mathrm{ab}}$ \\
\hline AHP SC $31 / 37$ & $53.1^{(\mathrm{ab})}$ & $44.4^{(\mathrm{b})}$ & $43.8^{(\mathrm{bcd})}$ & $47.0^{\mathrm{ab}}$ \\
\hline GW Ejulu-L & $47.4^{(b)}$ & $46.0^{(b)}$ & $38.9^{(d)}$ & $44 .^{1 b}$ \\
\hline TRFCA SFS 150 & $48.6^{(\mathrm{ab})}$ & $58.2^{(a)}$ & $41.6^{(\mathrm{cd})}$ & $49.3^{\text {ab }}$ \\
\hline TRFK $301 / 5^{\star}$ & $49.7^{(a b)}$ & $44.3^{(\text {b) }}$ & $46.3^{(\mathrm{abc})}$ & $46.7^{\mathrm{ab}}$ \\
\hline AHP SC 31/37* & $55.9^{(a)}$ & $54.9^{(a)}$ & $43.0^{(\mathrm{bcd})}$ & $51.2^{\mathrm{a}}$ \\
\hline TRFK $301 / 4^{*}$ & $50.6^{(a b)}$ & $51.3^{(a b)}$ & $47.4^{(a b)}$ & $49.8^{\mathrm{ab}}$ \\
\hline GW Ejulu-L* & $47.9^{(a b)}$ & $51.3^{(a b)}$ & $51.5^{(a)}$ & $50.2^{\mathrm{ab}}$ \\
\hline Mean & $50.5^{\mathrm{ab}}$ & $50.7^{a}$ & $44.2^{b}$ & 48.5 \\
\hline
\end{tabular}

${ }^{*}$ Clones in Kangaita sub-station (kirinyaga district); the others at Timbilil (Kericho); a,b-means followed by the same letter are not significantly different at $P \geq 0.05 \%$ level, and ${ }^{(a, b, c, d)}$ means followed by same letters are not significant different at $P \geq 0.05 \%$ level within the season

Genotype GW Ejulu-L at Timbilil, had a significantly low pollen germination rate (47.4\%) in the early season, compared to genotype AHP SC $31 / 37$ at Kangaita, that had the highest germination percentage (55.9\%). In the midseason, pollen germination ranged from $44.3 \%$ (TRFK 301/5) to 58.2\% (TRFCA SFS 150). Late season the germination ranged from $38.9 \%$ for genotype GW Ejulu-L at Timbilil, to $51.5 \%$ for GW Ejulu-L at Kangaita. Also there were significant differences among seasons and clone by season interaction effects during the year (Table 3). The weather conditions over the three seasons during flowering were different.

The effect of environmental conditions on pollen vaiability was evaluated on two genotypes, i.e. clones AHP SC31/37 (assamica variety and GW Ejulu-L sinensis variety) that were planted at both test sites. The effect of specific environmental parameters, i.e., rainfall, relative 
humidity and temperature on pollen viability was used for this analysis ( $r=0.68$, Fig. 2). No determined using linear correlation analysis. significant $(\mathrm{P}>0.05)$ correlation was found Mean germination revealed significant positive between the pollen germination and relative correlation with temperature in the two genotypes humidity, nor with rainfall during the study (data not shown).

TABLE 3. Weather variables during the flower sampling seasons

\begin{tabular}{|c|c|c|c|c|c|c|}
\hline & \multicolumn{2}{|c|}{ March (early) } & \multicolumn{2}{|c|}{ May (mid) } & \multicolumn{2}{|c|}{ July (late) } \\
\hline & Timbilil & Kangaita & Timbilil & Kangaita & Timbilil & Kangaita \\
\hline Air Temperature $\left({ }^{\circ} \mathrm{C}\right)$ & 17.6 & 17.2 & 16.0 & 16.8 & 15.2 & 13.4 \\
\hline Rainfall (mm) & 113.9 & 84.2 & 362.8 & 528.7 & 194.8 & 82.2 \\
\hline Humidity (\%) & 62 & 81 & 81 & 91 & 69 & 94 \\
\hline
\end{tabular}

Figure 2. Correlation between in-vitro pollen germination and temperature in tea ( ${ }^{*}$ significant at $P<0.05$ ).

\section{DISCUSSION}

There was significant variation in pollen viability among and between the Camellia sinensis genotypes in the seed orchards. Such differences suggest pollen competition leading to unequal reproductive success in the tea species. These results corroborate with those of an earlier study that had reported considerable variation in pollen viability between and among tea genotypes (Wachira and Kamunya, 2005). This has further been demonstrated in other plants (Nakamura and Wheeler, 1992; Skroppa and Lindgren, 1994). Nikkanen et al. (2000) found that pollen germination was similar both under in vitro and in vivo conditions, although it occurred faster in the former validating the use of in vitro techniques to establish pollen fitness as done in this study.

Through the differential pollen viability in our study, the reproductive biology of $C$. sinensis provides an opportunity for male gametophyte competition. However, a late-acting selfincompatibility system that constrains selfing has been reported in the species (Wachira and Kamunya, 2005). Thus, the genotypes homozygous for lethal, sublethal or defective genes are eliminated either by early abortion of zygotes or, later on, through embryo competition, a feature that might affect the results of 
gametophyte competition in this species. The significant seasonal variation in pollen germination and a high early to mid-season germination is an indication that pollination is most effective in the early to mid-season but pollen fitness reduces towards the late season. Clonal variability is also evident.

Although data on seed is unavailable, the current study indicates that hybridisation work in tea needs to be programmed so as to synchronise with seasons when optimal success is expected. It should also be programmed taking into account the differences between breeding parents.

The results of the present study show that the fitness of the $C$. sinesnsis pollen with respect to the germination ability varies. These may be caused by a number of factors like the duration for which anthers continue shedding pollen and the range of environmental factors to which they were exposed. Whereas the germination capacity of pollen from genotype AHP SC31/37 was not greatly influenced by environmental factors, the difference in pollen germination in genotype GW Ejulu-L between the two sites was greater. This study, therefore, suggests that pollen germination among the test genotype is affected by environment and that the $C$. sinensis genotypes have adapted to produce fast-germination pollen for different environmental conditions. Genotype AHP SC31/37 is an Assamica variety, while genotype GW Ejulu-L is a Sinensis (Chine type). From the above results, it is evident that pollen viability of the Assamica has a low response to different environmental conditions than to the China variety.

The stable performance of a tea genotype over wide range of environments is generally desirable (Wachira et al., 2002). Our results indicate that pollen fitness in Assamica tea is stable across environments. This, among others, could be a possible reason for the wide adoption of the Assamica variety worldwide compared to the other varieties (Paul et al., 1996). Indeed, nearly all the popular cultivars in Kenya are of Assam variety. Nikkanen et al. (2000), however, pointed out that genotype-environment interactions in pollen performance promote the maintenance of genetic variation within populations even if pollen performance is related to fitness and that some environmental signals during the reproductive process taking place in the female flowers, may cause variation in the phenology traits of the progeny. In tea seed orchards, these phenomena may contribute to the variable genetic composition of seed produced in different seasons or years.

The positive correlation between pollen germination and temperature suggested interaction between genotype and the environment (McLaren and Wehner, 1992). During tea flowering, the weather conditions in both sites differed considerably from year to year; the daily temperatures varying from +15.2 to $17.6^{\circ} \mathrm{C}$ during the experimental period, with a mean of $+16.4^{\circ} \mathrm{C}$ in Timbilil and from +13.4 to $+17.2^{\circ} \mathrm{C}$ with a mean of $15.8^{\circ} \mathrm{C}$ during the same period in Kangaita. Overall, field conditions were cooler at Kangaita that at the Timbilil site.

The experiment also suggested a relationship between flowering and rainfall (personal observation). Flowering commenced with the onset of the long rainfall (March/April) and flower production also varied considerably among the tea genotypes and varieties. It appeared that good rainfall is an important requirement for flowering; flower numbers reduced drastically with the break of the long rains in July. The Cambod variety was most prolific with flowering occurring almost throughout the year.

In conclusion, the significant variation in pollen viability found among the $C$. sinensis genotypes in our study indicates a potential for male gametophyte competition. Together with the observed genotype-environmental interactions in pollen performance, competition may contribute to the variable genetic composition of the seed produced in the tea seed orchards. The magnitude of the effects of pollen viability can, however, be assumed to be smaller than the effects of variations in flowering abundance and phenology within the seen orchard and of pollination by non-orchard sources. Male gametophytic competition in $C$. sinensis isolated seed orchards will be further studied by evaluating fruit/seed set from controlled self-and cross-pollination. 


\section{Male gametophyte competition among Camellia sinensis genotypes \\ ACKNOWLEDGEMENT \\ daffodil Narcissus triandrus. Heredity 96: 262-270.}

The authors thank the Tea Research Foundation of Kenya (TRFK) Botany staff for technical assistance. This paper is published with the permission of the Director, TRFK.

\section{REFERENCES}

Brooking, I.R. 1979. Male sterility in Sorghum bicolor induced by low night temperature. II. Genotypic differences in sensitivity. Australian Journal of Plant Physiology 6: 143-147.

Davis, L.E., Stephenson, A.G. and Winsor, J.A. 1987. Pollen competition improves performance and reproductive output of the common Zucchini squash under field conditions. Journal of American Society for Horticultural Science 112: 712-716.

Dogterome, M.H., Winston, M.L. and Mukai, A. 2000. Effect of pollen load size and source (self, outcross) on seed and fruit production in high bush blue berry cv. 'Bluecrop' (Vaccinium corymbosum; Ericaceae). American Journal of Botany 87: 1584-1591.

Farwing, N., Randrianirina, E.F., Voigt, F.A., Kraemer, M. and Böhning-Gaese, K. 2004. Pollination ecology of the dioecious tree Commiphora guilluminii in Madagascar. Journal of Tropical Ecology 20: 307-316.

Free, J.B. 1993. Insect pollination of crops. Academic press, London, UK.

Goal, M.L. and Fox, J.E.D. 2002. Reproductive potential of Acacia species in the central wheatbelt: Variation between years. Conservation Science of Western Australia 4(3): 147-157.

Genstat 5. 1987. Statistical Department, Rothamsted Experimental Station, Harpenden, Hertfordshire AL5 2JQ, Release 2.

Heslop-Harrision, J., Heslop-Harrison, Y. and Shivanna, K.R. 1984. The evaluation of pollen quality and a further appraisal of the fluorochromatic (FCR) test procedure. Theoretical and Applied Genetics 67: 367375.

Hodgins, K.A. and Barrett, S.C.H. 2006. Mating patterns and demography in the tristylous
Kameyama, Y., Isagi, Y. and Nakagoshi, N. 2002. Relatedness structure in Rhododendron metternichii var, hondoense revealed by microsatellite analysis. Molecular Ecology 11:313-321.

Kutubidze, V.Vl. 1958. Intraverietal supplementary pollination of the tea plant with pollen mixture. Agrobiologiya 4: 53-56.

Lansac, A.R., Sullivan, C.Y., Johnson, B.E. and Lee, K.W. 1994. Viability and germination of the pollen of sorghum (Sorghum bicolor (L) Moech). Annals of Botany (London) 74: 2733.

McLaren, N.W. and Wehner, F.C. 1992. Preflowering low temperature predisposition of sorghum to sugary disease (Claviceps africana). Journal of Phytopathology 135: 328-334.

Nakamura, R.R. and Wheeler, N.C. 1992. Pollen competition and paternal success in Douglasfir. Evolution 46: 846-851.

Nikkanen, T., Aronen, T., Häggman, H. and Venäläinen, M. 2000. Variation in pollen viability among Picea abies genotypespotential for unequal paternal success. Theoretical and Applied Genetics 101:511518.

Paul, S., Wachira, F.N., Powell, W. and Waugh, R. 1996. Diversity and genetic differentiation among populations of India and Kenyan tea (Camellia Sinensis (L.) ). NKunzte) revealed by AFLP markets. Theoretical and Applied Genetics 94: 255-263.

Skroppa, T. and Lindgren, D. 1994. Male fertility variation and non-random segregation in pollen-mix crosses of Picea abies. Forest Genetics 1: 13-22.

Stone, J.L., Thomson, J.D. and Dent-Acosta, S.J. 1995. Assessment of pollen viability in handpollination experiments: A review. American Journal of Botany 82: 1186-1197.

Sun, Y., Suksayretrup, K., Kirkham, M.B. and Liang, G.H. 1991. Pollen tube growth in reciprocal interspecific pollinations on Sorghum bicolor and S. versicolor. Plant Breeding 107: 197-202. 
Tuinstra, M.R. and Wedel, J. 2000. Estimation of Wachira, F.N., Ng'etich, W. Omolo, J. and Mamati, pollen viability in grain Sorghum. Crop Science 40: 968-970.

G. 2002. Genotype X environment interaction for tea yields. Euphytica 127: 289-296.

Wachira, F.N. and Kamunya, S.M. 2005. Pseudoself-incompatinility in some tea clones (Camellia sinensis (L.) O. Kuntze). Journal Wilcock, C. and Neiland, R. 2002. Pollination failure in plants: why it happens and when it matters. Trends in Plant Science 7: 270-277. of Horticultural Science and Biotechnology 80(6): 716-720. 